\title{
Forming a regular surface topography of a cylindrical part using oscillating ironing
}

\author{
Semen Zaydess ${ }^{1}$, Nguen Van Hin ${ }^{2}$, Igor Bobrovskij ${ }^{3}$ \\ ${ }^{1}$ IRNITU, Irkutsk, Russia \\ ${ }^{2}$ Shao Do University, Vietnam \\ ${ }^{3}$ Togliatti State University, Tolyatti, Russian Federation
}

\begin{abstract}
A new technological practice for the formation of a regular surface topography by means of oscillating ironing is presented. The results are based on analytical calculations and experimental studies. Surface topography after oscillating ironing depends on workpiece rotation frequency, deforming tool advance, oscillation frequency, deforming tool amplitude and tilt angle. The influence of the oscillating ironing process parameters on the size and shape of contact patch is confirmed.
\end{abstract}

\section{Introduction}

An effective way to improve SPD methods is the use of additional oscillatory movements [1], which, apart from finishing hardening treatment, produce a regular topography of the hardened surface. The quality of the surface layer induces the performance characteristics such as wear and corrosion resistance, contact fatigue resistance, contact stiffness, tightness and others. Therefore, more and more attention has been paid lately to optimizing the quality of surfaces in contact. Particularly, microgeometry optimization of contacting surfaces should be highlighted. The solution to this problem is quite complicated, due to two factors: a variety of contacts in machinery and contact phenomena; a complex relationship of the service properties of contacts with microgeometry of contacting surfaces $[2,3]$.

At present, there is no practice for forming a regular surface topography which would fully satisfy the listed requirements. The method of oscillating ironing proposed and developed by the authors meets most of these requirements $[4,5]$.

As a result of the complex interaction of the given parameters, a microrelief is formed on the machined surface, consisting of sinusoidal grooves of various compositions and densities. The formation on the treated surface of a system of grooves intersecting each other in a certain pattern improves the lubrication of a friction pair. It was established [3] that these grooves capture lubricant and prevent the adhesion of the contacting surfaces of the friction pair; form on the part surface ordered irregularities of various shapes depending on the required operational characteristics and properties; create helical microsections on interfacing cylindrical surfaces; provide finish surface part treatment without engaging the time-consuming abrasive treatment. Below we consider a new technological practice for the formation of a regular microrelief using oscillating ironing. 
Schematic diagram of the oscillating ironing of cylindrical parts is shown in Fig. 1. As a working element, a plate is used having a rounding along the radius $R_{p r}$ at one of the ends. This part of the plate is a working element that is pressed against a rotating workpiece. The plate can rotate relative to the vertical plane by a certain angle $\alpha$ (see Fig. 1), and make an oscillating vertical motion $\left(n_{o c}\right)$ relative to the axis of the workpiece and move axially in the feed direction $S$.
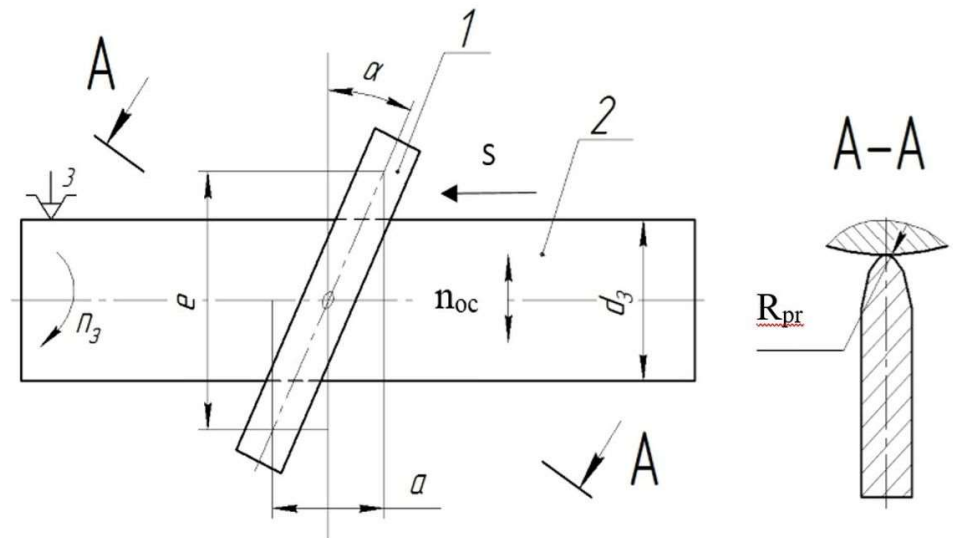

Fig. 1. Schematic diagram of the oscillating ironing of cylindrical parts: 1 - working tool; 2 - workpiece

The displacement of the tool - workpiece contact patch during oscillating ironing depends on the processing parameters: workpiece rotation frequency $\left(n_{3}\right)$, working tool feed $(S)$, oscillation frequency $\left(n_{o c}\right)$, amplitude $(a)$ and tilt angle of the working tool $(\alpha)$.

Oscillation of the tool with amplitude $e$ and frequency $n_{o c}$ in the vertical direction causes the contact patch to oscillate in the horizontal direction with the same frequency $n_{o c}$, but with the amplitude:

$$
a=e \sin \alpha,
$$

where $\alpha$-rotation angle of the working tool (see. fig. 1 ).

The presence of the angle $\alpha$ and the possibility of its regulation extends the technological capabilities of oscillating ironing. With the same oscillation amplitude of the tool, it is possible to obtain different amplitudes of the contact patch between the part and the tool, and it is possible to obtain larger values of the amplitude $a=e \sin \alpha$ at larger angle $\alpha\left(+90^{\circ}>\alpha\right.$ $\left.>-90^{\circ}\right)$.

When turning the working tool $\alpha \neq 0$, the contact patch path and the parameters that determine the modes of oscillating ironing are presented in fig. 2 . If the working tool is not rotated $\left(\alpha=0^{\circ} \Rightarrow a=e \sin \alpha=0\right)$, then a straight line is formed on the forming surface of the part, which, if there is a tool feed, transforms into a helical line.

The volumetric characteristics and relative position of the microrelief grooves depend on the ratio $i[6]$ :

$$
\mathrm{i}=\mathrm{n}_{\mathrm{oc}} / \mathrm{n}_{3}=[\mathrm{i}]+\{\mathrm{i}\},
$$

where [i] - the integer part of number $i$, and $\{i\}$ - fractional part of number $i$. 


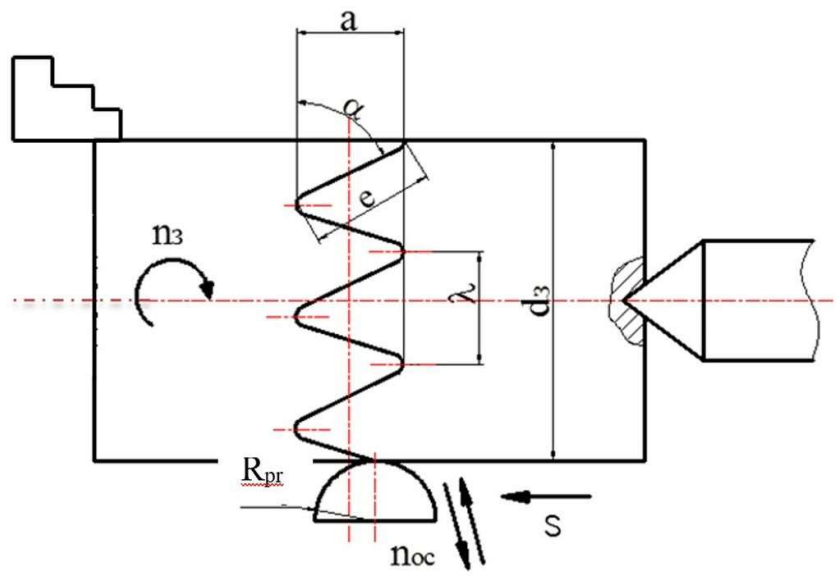

Fig. 2. Contact patch path during oscillating ironing

The integer part of the numerical value [i] shows how many times the wavelength $\lambda$ is laid along the circumference of the workpiece, and the fractional part $\{i\}$ - shows the magnitude of the displacement of the grooves relative to each other for each subsequent revolution.

The wavelength $\lambda$ is determined by:

$$
\begin{gathered}
\lambda=\mathrm{v}_{3} \cdot \mathrm{T} ; \\
\mathrm{v}_{3}=\pi \cdot \mathrm{d}_{3} \cdot \mathrm{n}_{3} ; \\
\mathrm{T}=\frac{1}{\mathrm{n}_{\mathrm{oc}}},
\end{gathered}
$$

where $v_{3}$ - workpiece rotation speed; $d_{3}$ - workpiece diameter; $\mathrm{T}$ - oscillation period of the deforming element.

Then

$$
\lambda=\pi d_{3} \frac{n_{3}}{n_{o c}}(M M)
$$

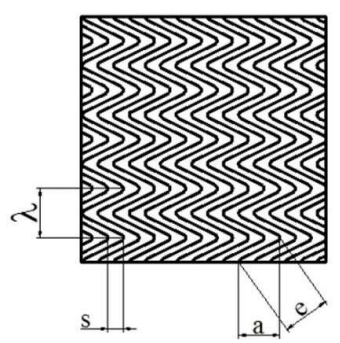

a)

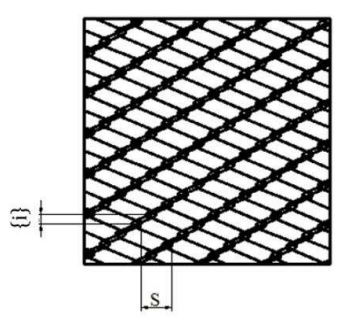

b)

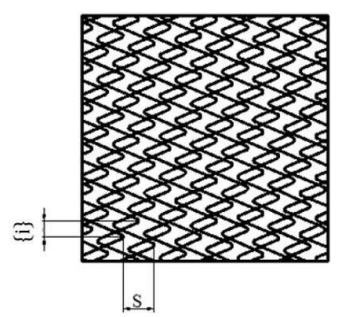

c)

Fig. 3. Correlation between the shape of the surface microrelief and the value $\{i\}$ : a) $\{\mathrm{i}\}=0$; б) $\{\mathrm{i}\}=0,25$; в) $\{\mathrm{i}\}=0,4$

Fig. 3 shows the patterns of grooves arrangement depending on the values of $\{i\}$. For $\{i\}$ equal to zero ( $i$ is an integer), there is no displacement of the grooves (see fig. 3a). If $1>\{\mathrm{i}\}$ $>0$ the grooves are arranged as shown in fig. $3 \mathrm{~b}$ and $3 \mathrm{c}$ (intertwine). The influence of the oscillating ironing parameters on the types of regular microrelief is described in [7].

2 Determination of tool - workpiece contact patches during oscillating ironing 
As is known from works [6,8], based on a system analysis of machining methods, the main function of static characteristics is to ensure a certain relative position of the tool and the workpiece during processing. Their choice is determined by the direction and magnitude of the acting forces, as well as the shape and relative position of the tool and the workpiece.

A special feature of contact deformation during ironing is the presence of a significant elastic deformation in the contact region. The plastic and elastic components of the deformation are comparable in magnitude, and in some cases, elastic deformation is predominant $[8,9]$.

In static indentation, the shape of the tool - workpiece contact is an ellipse (see fig. 4a). During ironing, the contact patch shape changes, see fig. $4 \mathrm{~b}$.

The shape and area of the contact patches between the tool and the workpiece in the absence of longitudinal feed was obtained by computer simulation in the NX7.5 program with parameters $d_{3}=20 \mathrm{~mm} ; R_{p \mathrm{r}}=4 \mathrm{~mm}$; preload $t=0.1 \mathrm{~mm}$; and in the presence of longitudinal feed of the working tool $(S=0.14 \mathrm{~mm} / \mathrm{rev})$ and workpiece rotation frequency $\left(n_{3}=100 \mathrm{rpm}\right)$.

Fig. 4 shows the shape of the tool - workpiece contact patches when changing the rotation angle of the working tool.
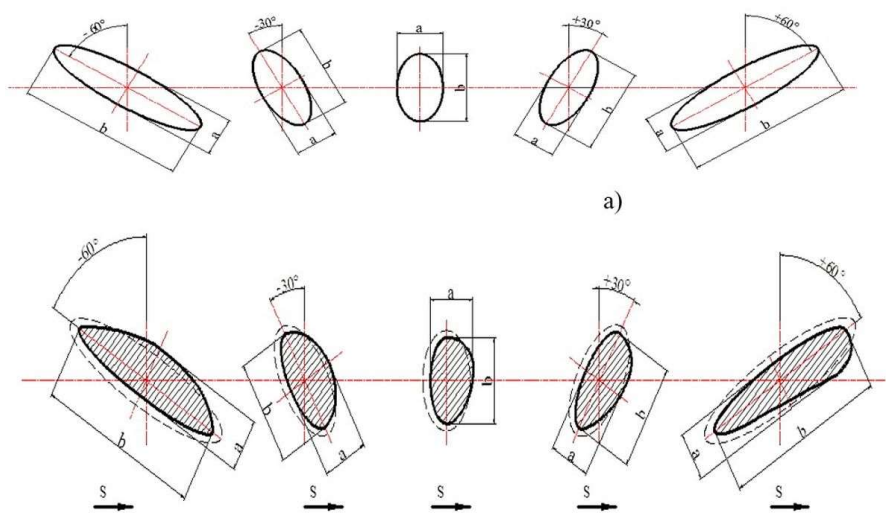

b)

Fig. 4. The shape of the tool - workpiece contact patch when changing the rotation angle of the working tool a) in the absence, b) in the presence of longitudinal feed

The shapes of the tool - workpiece contact patches represent a regular geometric figure (ellipse), which, when deformed, is distorted by the elastic-plastic deformation of the metal.

Table 1 shows the area and dimensions of the tool - workpiece contact patch in the absence of longitudinal feed. The calculations established that in the absence of longitudinal feed, the size of the contact patch does not depend on the direction of rotation of the working tool. With an increase in the rotation angle $\alpha$ from $0^{\circ}$ to $\pm 85^{\circ}$, the area of the contact spot increases by 11.8 times; patch width $a$ decreases by $14 \%$; patch length $b$ increases by 13.7 times. The most significant changes in geometric characteristics occur at rotation angles close to $90^{\circ}$.

Table 1. Geometric characteristics of the tool - workpiece contact patch in the absence of longitudinal feed

\begin{tabular}{|c|c|c|c|c|}
\hline $\boldsymbol{\alpha}^{\circ}$ & $\mathbf{0}$ & $\mathbf{3 0}$ & $\mathbf{6 0}$ & $\mathbf{8 5}$ \\
\hline $\mathrm{A}\left(\mathrm{mm}^{2}\right)$ & 3.94 & 4.54 & 8.04 & 45.95 \\
\hline $\mathrm{a}(\mathrm{mm})$ & 1.78 & 1.67 & 1.57 & 1.53 \\
\hline $\mathrm{b}(\mathrm{mm})$ & 2.82 & 3.46 & 6.52 & 38.26 \\
\hline
\end{tabular}


Table 2 gives the geometric characteristics of the tool - workpiece contact patch in presence of longitudinal feed.

Table 2. Geometric characteristics of the tool - workpiece contact patch in presence of longitudinal feed.

\begin{tabular}{|c|c|c|c|c|c|c|c|}
\hline $\boldsymbol{\alpha}^{\circ}$ & $\mathbf{- 8 5}$ & $\mathbf{- 6 0}$ & $\mathbf{- 3 0}$ & $\mathbf{0}$ & $\mathbf{+ 3 0}$ & $\mathbf{+ 6 0}$ & $+\mathbf{8 5}$ \\
\hline $\mathrm{A}\left(\mathrm{mm}^{2}\right)$ & 32.21 & 5.60 & 3.10 & 2.37 & 2.70 & 4.79 & 27.54 \\
\hline $\mathrm{a}(\mathrm{mm})$ & 1.34 & 1.37 & 1.43 & 1.50 & 1.42 & 1.34 & 1.31 \\
\hline $\mathrm{b}(\mathrm{mm})$ & 30.62 & 5.21 & 2.77 & 2.02 & 2.42 & 4.55 & 26.78 \\
\hline
\end{tabular}

In the presence of a longitudinal feed of the working tool and the rotation speed of the workpiece, the angle and direction of the working tool affect the size of the contact patch. With a positive direction of the angle $\alpha$ : area $A$ - increases 12.0 times; $b$ - increases by 13.3 times; $a$ - reduced by $13.0 \%$. With a negative direction of the angle $\alpha$ : $A$ - increases 13.6 times; $b$ - increases by 11.1 times; $a$-reduced by $11 \%$.

\section{Conclusion}

1. A new kinematics of the finishing and hardening treatment by oscillating ironing is proposed, which ensures the stability of the surface plastic deformation process.

2. A method of finishing and hardening treatment by oscillating ironing has been developed, which provides the possibility of surface plastic deformation of machine parts and the formation of a regular surface topography. Designed and manufactured a working tool and machine for oscillating ironing of cylindrical parts and the formation of a regular surface topography.

\section{References}

1. S.A. Zaydes, V.N. Yemel'yanov, M.Ye. Polov, Ye.Yu. Kropotkina, A.S. Bubnov, Deformiruyushchaya obrabotka valov (Izdatel'stvo IrGTU, Irkutsk, 2013)

2. Odintsov L.G., Uprochneniye i otdelka detaley poverkhnostnym plasticheskim deformirovaniyem: Spravochnik (Mashinostroyeniye, Moscow, 1987)

3. Yu.G. Shneyder, Tekhnologiya finishnoy obrabotki davleniyem: Spravochnik. (Politekhnika, Saint-Petersburg, 1988)

4. S.A. Zaides, Van Hinh Nguyen, Russian Engineering Research., 11, 859 (2018)

5. S.A. Zaydes, Van Hinh Nguyen, Fam Duck Phuong, Patent No. 2657263, RF, Bull. 16.

6. Yu.G. Shneyder, Ekspluatatsionnyye svoystva detaley s regulyarnym mikrorel'yefom (Mashinostroyeniye, Saint-Petersburg, 1982)

7. S.A. Zaydes, Van Hinh Nguyen, Uprochnyayushchiye tekhnologii i pokrytiya, 12, 62 (2017)

8. V.M. Smelyanskiy, Mekhanika uprochneniya detaley poverkhnostnym plasticheskim deformirovaniyem (Mashinostroyeniye, Moscow, 2002)

9. V.M. Smelyanskiy, V. Yu. Blumenstein, Mekhanika tekhnologicheskogo nasledovaniya na stadiyah obrabotki i ekspluatacii detalej mashin (Mashinostroyeniye, Moscow, 2007) 